\title{
Some Observations on the Value of Pre-Operative Treatment for the Surgical Patient in Relation to Anesthesia*
}

\author{
W. J. DeFries, M. D., Anesthetist, Toronto, Canada
}

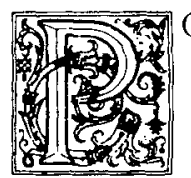

OST-OPERATIVE VOMITING has always been dreaded by the surgeon as well as by the anesthetist. If the patient is not nauseated after the operation, then the anesthetist is quick to take the credit for administering a good anesthetic, but if, on the other hand, persistent vomiting occurs, the surgeon, by his manipulations during the operation, was of course, undoubtedly to blame! But that time has passed when the expressions: "the patient took a good anesthetic" or "he took a poor anesthetic" can be used.

\section{Prophylaxis of Pre-Operative Treatment}

$a^{2}$

E ALL have seen patients who, even after an operation of short duration, during which time the anesthetic was administered br a skilled anesthetist, vo mit persistently. while others, after long operations, the anesthetic heing given by the junior interne, have recovered without even being nauseated. This would lead to the belief that certain persons are more prone to vomit than others, and so it is simply their misfortune. But investigators of this condition have come to the conclusion that natuse?. vomiting, distension, gas - pans. headache and other sumptoms of profound shock. which may end in death, are all symptoms of an acil intoxication, and, while post-operative treatment is helpful and sometimes curative, yet pre-operative treatment is very frequently prophylactic.

Reiman and Bloom found that after the administration of any of the alcohol group of anesthetics, ether, chloroform, and ethy\| chlorid, that the alkaline reserve of the plasma was diminished in every case. This did not occur when nitrous oxid-oxygen was used. It has been found that patients with a low alkali reserve before operation showed signs of acid-intoxication afterwards. Here it would secm is the reason for the postanesthetic sequelae. Reiman and other investigators have found that the condition of shock is always associated with an uncompensated acidosis. They believe that the protection of the patient from acidosis rests in limiting suboxidation and in supplying the body with alkali. Ammonia and the acidity of the urine are increased after anesthesia. The acids are neutralized as they are formed by sodium bicarbonate and ammonia. and, also, by other available but less easily mobilizable bases, such as calcium and magnesium. The salts of the acids are then excreted and thus eliminated from the body. 


\section{Anesthesia and Analgesia - October, 1922}

\section{Determining Alkali Reserve}

$I^{9}$ THEN the influence of the anesthetic is toward the depletion of the alkali reserve. and a low alkali reserve at the commencement of the operation results in an acidosed condition of the patient at the close, which is evidenced by persistent vomiting. distension, great pain and other sympioms already mentioned, then a treatment that will build up a good alkali reserve will be of decided benefit.

But all surgical patients are not in the need of further alkali treatment and too much alkali may br as harmful as too much acidity. Therefore, whether or not alkali should be given may be determincd by some test which reill indicate the alkali rescrve. A routine estimation of this factor of safety is desirable. The rate of the respiration should be noted, and Yandell Henderson's simple test for acidosis employed, namely, the ability to hold the breath for the normal period of forty seconds. If there is a suspicion that the alkali reserve is not what it should be, then one of the clinical methods for estimating it should be used.

Probably the simplest and most widely applicable of these is the determination of the percentage of carbon dioxid in the alveolar air by Henderson's method.

\section{Alkali Therapy and Diet}

$\pi$

HEN this test indicates the need of adtitional a'kali. sodium bicarbonate should be given until urine becomes alkaline or neutral at least, to litmus.
Wm. H. Morris points out that while the administration of sodium bicarbonate increases the alkali reserve, the value of this treatment is shown post-operatively, and he claims that sodium bicarbonate given before operation is a rational precautionary measure against postoperative vomiting.

The object of the use of sodium bicarbonate is to (1) change the reaction of the urine from acid to alkali; (2) restore the normal carbon dioxid tension in the alveolar air; (3) restore the normal bicarbonate reserve of the plasma.

The surgical patient, whenever possible, should be placed on a special diet for three or four days before operation. This diet should provide freely of carbohydrate, alkali and water. It should include well-cooked cereals, with plenty of sugar, white bread or toast, malted milk, prepared foods containing maltose and dextrose, baked potatoes, all vegetables, and fruits as oranges, grape-fruit and apples. It should be remembered that organic fruit-acids are quickly oxidized, so that feeding of citrus fruits is equivalent to the administration of alkali in an agreeable form. For the alkali element of the treatment carbonates and bicarbonates of sodium, calcium and magnesium should be given. Sodium bicarbonate in one-dram doses and calcium acetate in one-halfdram doses every four hours with plenty of water have proved to be very efficient treatment. According to Sanders, the idea is to have the patient come to operation with the urine alkaline to litmus and passing at least fifty ounces in twentyfour hours. 


\section{Anesthesia and Analgesia - October, 1922}

Role of Narcosis and Anesthesia

ฮั HE USE of alkaloids in combination with general anesthetics is the common practice of many surgeons, and does much to prevent anesthetic complications. When morphin, with or without atropin, is given preliminary to anesthesia, the patient comes to the operating-room in a tranquil frame of mind. Nervous excitement is absent, the dread of the operation is greatly lessened. It should be remembered that fear is a large contributing factor in the production of acidosis and also, contributes to shock. Therefore, the reduction of fear is important.

Many operations can be done under an extremely light narcosis, which, without medication, would have called for a deep ether anesthesia. The patient is then, while on the operating table, in a condition of safety, also, from the small amount of anesthetic employed, has less post-anesthetic vomiting, thus the risk of subsequent acidosis is lessened. The risk of ether-bronchitis is practically eliminated. The effect of morphin on the respiratory center must he remembered. . It is a depressant reducing the frequency and depth of the respirations. Ether is a respiratory stimulant. The result of their combination is the production of a regular type of breathing. But with the use of morphin the anesthetist must allow for the stage of analgesia produced by it. He must not be giving his usual anesthesia ignoring the light anesthesia produced by morphin. As long as the patient suffers no pain, is relaxed, and does not embarrass the operator by reflex movements, all requirements are satisfied, and the zone of safely, which separates the stage of maintenance of the anesthetic from the point of respiratory arrest, is lengthened and the patient's return to consciousness hastened. The morphin at the close of the operation still assists by keeping the patient in a mild stag? of analgesia which is sufficient to bridge over that stage of acute pain from which patients, not so protected, frequently complain.

\section{Loss of Sleep, Dehydration and Purgation}

OWO factors which promote (9) post-operative shock are loss of sleep and dehydration. In the preparation for any abdominal operation these factors should be considered carefully The patient must be ensured a proper rest on the night preceding the operation. If of nervous temperament, a sedative, such as reronal, can be given. It is not advisable to employ pre-operative purgation for large amounts of fluids are lost by the purge and the night that should be spent in sleep and comfort is made a veritable nightmare. It has been shown by Alvarez and Taylor that the purged intestine is less able to empty itself and is more distended than one that has not been purged. All surgeons have noted how much easier it is to operate upon the emergency case with collapsed bowel than upon those who have been thoroughly prepared with their empty but distencled coils, and yet we are slow to realize that purgation is not only unnecessary but harmful. It is better to use a soap-suds enema on the night before operation and another in the morning except in the ob- 


\section{Anesthesia and Analgesia - October, 1922}

stinately constipated who can be given a mild laxative, such as cascara or phenolphthalein. at night and the enema in the morning.

\section{Conclusions}

$Q^{R}$ ROM the observation of several hundred cases during the past year, who have had pre-operative treatment for several days before their operations, and several hundred other cases who were not specially prepared, it has leen noticed that the majority of cases in the prepared class made a much quicker convalescence than lit! the others. In fact, by the third day the prepared patients were feeling like patients who were a week over their operation. They had very much less vomiting, many were only slightly nauseated and only about 2 per cent appeared to have not been benefited. There was a marked absence of post-operative distension and pain. All these laticnts were given ether or chloroform and ether by the semi-open method, that is, with the ordinary mask covered by gauze and a towel used as a further covering to promote some rebreathing at times.

The most marked results were seen in cases who formerly had several anesthetics followed in each instance by severe vomiting but no romiting occurred when pre-operative preparation was used.

31 Bloor Street West.

I falling blood pressure signifies a falling circulation, and this in turn includes an anemia of the inlluar centers, the respiration, the vaso-constrictors, and the vasodilators. So if a substance can be used in transfusion and maintain the blood pressure, there will be no anemia of blood centers. Also acidosis, which may be brought about by museular metabolism, or crushing of tissues, is roughly an increased carbon dioxid volume and a diminisher bicarbonate content of plasma. Thus with a better minintained circulation renal and pulmonary vascularity is at its best level, thereby favoring the elimination of acids and gases.

Gum-glucose solution increases the volume of the circulating blood, and maintains it at this higher level, and thus raises the blood pressure. combats a tendency to acidosis, furnishes a certain amount of stimulation, and furnishes a certain amount of food. 